Article

\title{
Modelling Shear Induced Diffusion Based Particle Segregation: A Basis for Novel Separation Technology
}

\author{
Ivon Drijer ${ }^{1,2}$ and Karin Schroën ${ }^{1, *}$ \\ 1 Laboratory of Food Process Engineering, Department of Agrotechnology and Food Sciences, \\ Wageningen University, Bornse Weilanden 9, 6708 WG Wageningen, The Netherlands; ivon.drijer@wur.nl \\ 2 Veco B.V., Karel van Gelreweg 22, 6961 LB, Eerbeek, The Netherlands \\ * Correspondence: karin.schroen@wur.nl; Tel.: +31-317-483-396
}

Received: 28 May 2018; Accepted: 19 June 2018; Published: 20 June 2018

\begin{abstract}
Shear induced diffusion (SID) based flow segregation is a technique that can be used for concentration and fractionation purposes, and it has the potential to become an economical and sustainable alternative for e.g., membrane separation. When compared to conventional microfiltration, problems related to fouling and cleaning are expected to be minimal. To make the best use of the opportunities that this technique holds, detailed insights in flow and particle behavior are needed. Modelling this process allows for us to chart particle segregation in flow, as well as the effect of suspension removal through a pore and the restoration of the flow profile after the pore. As a starting point, we take the computation fluid dynamics (CFD) model that is presented in a previous study. A difference in channel height to particle diameter ratio influences the entrance length of the SID profile as well as its fully developed profile. When extracting liquid through one pore, particles are systematically transmitted at a lower concentration (59-78\%) than is present in the bulk. The recovery lengths of the SID profile after the pore were short, and thus pores can be placed at realistic distances, which forms a good foundation for further design of this novel separation technology that will ultimately be applied for fractionation of particles taking relatively small differences in diffusive behavior as a starting point.
\end{abstract}

Keywords: shear induced diffusion; computational fluid dynamics; particle separation; concentrated suspensions; parameter study; effect of pores

\section{Introduction}

The fractionation and concentration of particles is used in many industries [1-3], for which different methods are available that mostly depend on the size of the particles that need to be separated. Dijkshoorn et al. (2017) distinguish three different categories in their recent review: particles that are smaller than $10 \mathrm{~nm}$ that can be separated using adsorption or ultrafiltration, particles in the range of 1-10 $\mu \mathrm{m}$ that can be separated by microfiltration or specific microfluidic devices, and particles larger than $10 \mu \mathrm{m}$ that can be separated by centrifugation or settling when having a sufficient density difference [4]. In the current paper, we are interested in separating particles in the range of $1-10 \mu \mathrm{m}$ and focus on a concept that combines insights that were obtained for microfiltration and microfluidic devices.

In conventional microfiltration particles are carried towards a membrane via convection, where they are then retained creating a concentration polarization layer, and, in due time, a cake layer. These layers will have an influence on the trans-membrane pressure, which results in a reduction of the flux $[5,6]$, and changing retention or selectivity of the membrane as a function of time $[5,6]$. In micro-structured devices and channels, particle behavior in flow can also be used to achieve separation or fractionation. For example, deterministic ratchets make use of the displacement of 
particles around precisely placed objects [7]; based on a critical size, particles will follow a particular streamline or be displaced [7]. Fluid skimming makes use of fluid flow to carry a particle across a pore (similarly to microfiltration at high cross flow), and is termed an industrially promising technique because of its scalability by some authors $[4,8]$.

In the current paper, we focus on shear induced diffusion based segregation that takes place in relatively narrow channels, and has been suggested for particle fractionation that is based on experimental observations [9]. Here, we use modelling studies to chart process parameter effects (e.g., channel dimensions, flow velocity, concentration profiles, and restoration thereof after a disturbance) and achieve systematic insights in process behavior.

\section{Shear Induced Diffusion Based Segregation}

Nowadays, industries not only require and demand a high performance at low costs, but also look at the environmental impact of their processes. In this sense, making use of the principle of shear induced diffusion is an interesting option since it can be operated at much lower energy impact than e.g., microfiltration that in itself is already not that high in energy impact [9]. Shear induced diffusion (SID) is one of the natural migration mechanisms of particles and relies on collective particle behavior that directs particles away from a channel wall. Next to SID, there is Brownian diffusion and inertial lift [5]; see also Figure 1. Brownian diffusion includes the tendency of particles to move in a random direction, and inertial lift includes the effect of the fluid surrounding the particles, which directs individual particles away from the channel wall.

To distinguish the different particle migration mechanisms, the dimensionless particle Reynolds number and Péclet number are used, which are indicative of the ratios between the different forces that are acting on the particles [10]. SID is dominant for particles in the range of 1 to $10 \mu \mathrm{m}$, with a particle Reynolds number lower than one and a Péclet number that is higher than one (Figure 1).

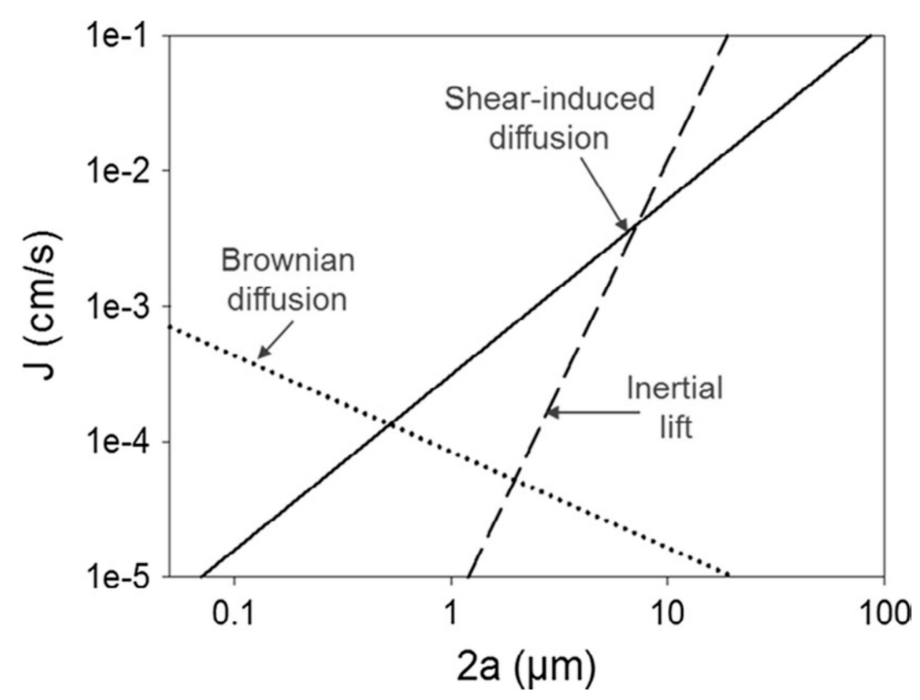

Figure 1. Flux versus the particle diameter for different migration mechanisms (Graph is reprinted from Separation and Purification Technology, 174, Karin Schroën; Anna van Dinther and Regine Stockmann, Particle migration in laminar shear fields: A new basis for large scale separation technology?, 372-388, 2017, with permission from Elsevier, original is from Davis [11]).

Considerable effort is put into understanding the principle of shear induced diffusion [12-20] that is especially relevant at high volume fractions and it causes particles to interact and move towards a region with low shear (i.e., the center of a channel) [21]. Depending on the size and volume fractions of small and large particles the former or latter will predominantly move towards the center of the channel when using particles of different sizes [19]. In a monodisperse suspension, the particles will 
concentrate near the center, which is a lead for novel concentration processes based on shear-induced diffusion when removing the particle-free liquid that is close to the wall (Figure 2) [16,17].

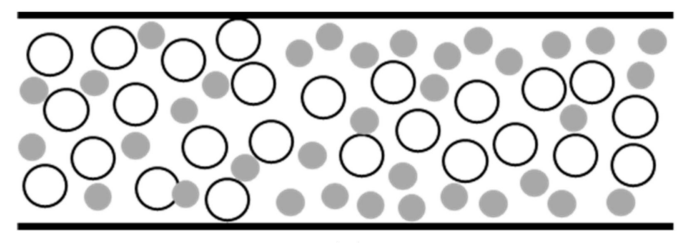

(a)

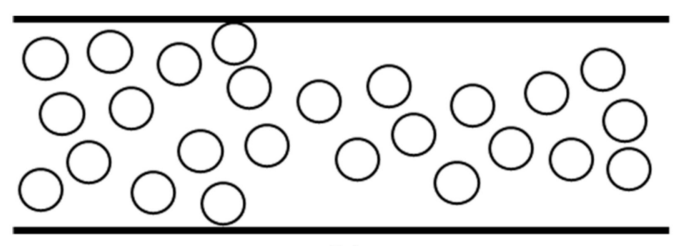

(b)

Figure 2. Schematic representation of the segregation principle of shear induced diffusion for a bidisperse (a) and monodisperse (b) suspension.

After the segregation of particles has taken place in a closed channel, a porous section can be considered to either concentrate particles, or separate different sized particles in case of a bidisperse or polydisperse suspension [21,22]. Since the segregation already takes place inside the closed channel, the pores in the porous section do not need to have an exclusion effect and can therefore be larger than the size of the particles, unlike regular membrane filtration. The large pores have much lower tendency to block, and the formation of a cake layer is much less likely to occur, even while working with high particle volume fractions [21]. This allows for process intensification, and it will reduce cleaning costs, which in turn is expected to reduce the environmental impact of the process considerably [22].

The effect of SID has been experimentally investigated by Van Dinther and coworkers [21-23], and they found the high separation efficiency of a bidisperse suspension in a system consisting of a non-porous channel and a porous region, depending on the process conditions used. In order to facilitate process design, we have set up and validated a CFD model, which describes the effect of SID in a non-porous channel only, for a monodisperse suspension in earlier work [10]. In the current study, this CFD model will be used as a starting point for the description of the whole process that also consists of a porous section (Figure 3). The particle profile near the pore, and the re-constitution of the concentration profile after the pore are of core importance to this novel process; therefore, we focus on these aspects. This information will in later studies be used as a basis for fractionation of particles that are similar in size.

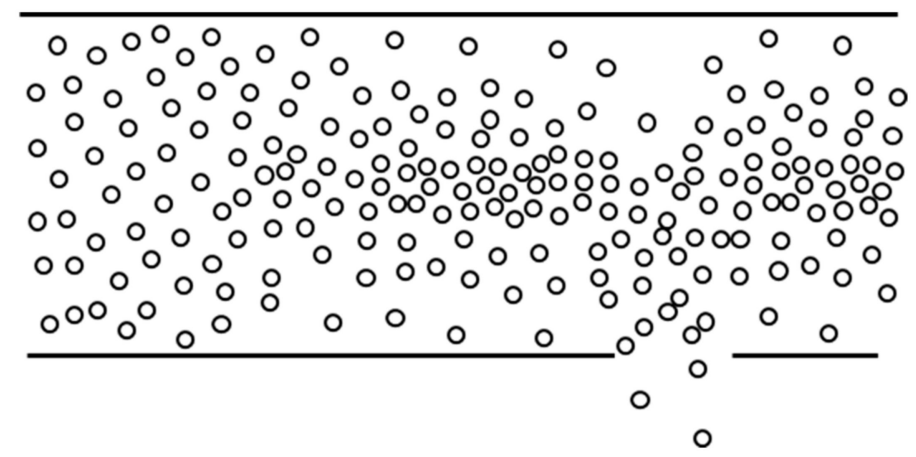

Figure 3. Schematic view of the process considered in this study; please note the change in concentration profile close to the pore that will be discussed in detail in the results section.

\section{Model Development}

The interested reader is referred to a previous study [10] for the details of the CFD model that describes the SID process and its validation; here, we limit ourselves to a summary, and highlight the additions made to the previously established model. The 'Multiphase Segregated Flow Model' of the commercial CFD software STAR-CCM+ (CD-adapco, London, UK) is applied, which uses 
an Euler-Euler type of formulation that enables us to do the fast calculations that are needed for parameter studies.

\subsection{Governing Equations}

Because of the Euler-Euler formulation separate equations are used for the particle and fluid phase for both momentum and mass. A phase momentum source term describes SID for the main channel in these equations. To make use of the principle of SID, the flow needs to be laminar (turbulence will destroy the concentration profiles). Furthermore, non-reactive hard and inert particles are used that do not dissolve, and do not stick to the walls. The above-mentioned conditions allow for us to assume that there are no internal forces and phase mass source terms. Also, a constant density and an absence of mass transfer between phases can be assumed. This results in the equations given next.

Continuity equation for the fluid:

$$
\frac{\partial}{\partial t} \int_{V}\left(1-\alpha_{p}\right) \rho_{f} d V+\oint_{A}\left(1-\alpha_{p}\right) \rho_{f} v_{f} d a=0
$$

Continuity equation for the particles:

$$
\frac{\partial}{\partial t} \int_{V} \alpha_{p} d V+\oint_{A} \alpha_{p} v_{p} d a=0
$$

Momentum equation for the fluid:

$$
\begin{gathered}
\frac{\partial}{\partial t} \int_{V}\left(1-\alpha_{p}\right) \rho_{f} v_{f} d V+\oint_{A}\left(1-\alpha_{p}\right) \rho_{f} v_{f} \otimes\left(v_{f}-v_{g}\right) d a=-\int_{V}\left(1-\alpha_{p}\right) \nabla p d V \\
+\int_{V}\left(1-\alpha_{p}\right) \rho_{f} g d V+\oint_{A}\left(1-\alpha_{p}\right) \tau_{f} d a-\int_{V} F_{p f}^{D} d V-\int_{V} F^{S I D} d V
\end{gathered}
$$

Momentum equation for the particles:

$$
\begin{gathered}
\frac{\partial}{\partial t} \int_{V} \alpha_{p} \rho_{p} v_{p} d V+\oint_{A} \alpha_{p} \rho_{p} v_{p} \otimes\left(v_{p}-v_{g}\right) d a=-\int_{V} \alpha_{p} \nabla p d V+\int_{V} \alpha_{p} \rho_{p} \mathrm{~g} d V \\
+\oint_{A} \alpha_{p} \tau_{p} d a+\int_{V} F_{p f}^{D} d V+\int_{V} F^{S I D} d V
\end{gathered}
$$

Here, $\alpha_{i}$ is the volume fraction of phase $i(-)\left(\sum_{i} \alpha_{i}=1\right), \rho_{i}$ the density of phase $i\left(\mathrm{~kg} / \mathrm{m}^{3}\right), v_{i}$ the velocity of phase $i(\mathrm{~m} / \mathrm{s}), v_{g}$ the grid velocity $(\mathrm{m} / \mathrm{s}), p$ the pressure $(\mathrm{Pa}), g$ the gravity vector $\left(\mathrm{m} / \mathrm{s}^{2}\right)$, $\tau_{i}$ the molecular stresses of phase $i(\mathrm{~Pa}), F^{D}$ the drag force $\left(\mathrm{N} / \mathrm{m}^{3}\right)$, and $F^{S I D}$ the shear induced diffusion force $\left(\mathrm{N} / \mathrm{m}^{3}\right)$. The shear induced diffusion force is given below in Equation 5 for which the closure relations are given in Table 1.

$$
F^{S I D}=\frac{\left(D_{\alpha_{p}} \nabla \alpha_{p}+D_{\dot{\gamma}} \nabla \dot{\gamma}\right)}{M}
$$

With $\dot{\gamma}$ the shear rate $(1 / \mathrm{s}), D_{\alpha_{p}}$ the volume fraction dependent diffusion coefficient $\left(\mathrm{m}^{2} / \mathrm{s}\right), D_{\dot{\gamma}}$ the shear rate dependent diffusion coefficient $\left(\mathrm{m}^{2}\right)$, and $M$ the mobility $\left(\mathrm{m}^{2} /(\mathrm{Pa} \cdot \mathrm{s})\right)$. The drag force is described by the following generic relation:

$$
F_{i j}^{D}=A_{i j}^{D}\left(v_{j}-v_{i}\right)
$$

Here, $A_{i j}^{D}$ is the linearized drag coefficient $\left(\mathrm{Pa} \cdot \mathrm{s} / \mathrm{m}^{2}\right)$. For more details about the drag force see Table 2 . 
To make the key points of our numerical model clearer, a flow chart is presented in Figure 4 that gives the most important points used in our model.

Table 1. Closure relations needed for the shear induced diffusion force.

\begin{tabular}{|c|c|c|}
\hline Closure Relation & Reference & Equation \\
\hline$\eta$ & $\begin{array}{l}\text { Krieger-Dougherty } \\
\text { relation }\end{array}$ & $\eta_{f}\left(1-\frac{\alpha_{p}}{\alpha_{\max }}\right)^{[\eta] \alpha_{\max }}$ \\
\hline$M$ & Vollebregt et al. [14] & $\frac{2}{9} \frac{a^{2}}{\eta_{f}} \alpha_{p} f\left(\alpha_{p}\right)$ \\
\hline$D_{\alpha_{p}}$ & Vollebregt et al. [14] & $\begin{array}{c}\frac{2}{9} \dot{\gamma} a^{2}\left(1-\alpha_{p}\right)^{2} \bullet \\
1.5 \frac{\widetilde{\alpha_{p}}}{\alpha_{\max }}\left(1+\widetilde{\alpha_{p}}\left(1-\widetilde{\alpha_{p}}\right)^{-1}\right)\end{array}$ \\
\hline$D_{\dot{\gamma}}$ & Vollebregt et al. [14] & $\frac{2}{9} a^{2}\left(1-\alpha_{p}\right)^{2} \bullet 0.75{\widetilde{\alpha_{p}}}^{2}$ \\
\hline$f\left(\alpha_{p}\right)$ & Vollebregt et al. [14] & $\left(1-\alpha_{p}\right)^{2}\left(1-\widetilde{\alpha_{p}}\right)^{2^{p}}$ \\
\hline$\dot{\gamma}$ & Miller et al. [16] & $\frac{d v}{d y}+\frac{a \cdot \mathbf{v}_{\max }}{H^{2}}$ \\
\hline
\end{tabular}

Table 2. Relations used for the drag force.

\begin{tabular}{|c|c|c|}
\hline Parameter & Description & Equation \\
\hline$A_{i j}^{D}$ & & $C_{i j}^{D} \frac{1}{2} \rho_{f}\left|v_{j}-v_{i}\right| \frac{a_{i j}}{4}$ \\
\hline$C_{i j}^{D}$ & & $f_{i j}^{D} C_{i j \infty}^{D}$ \\
\hline$C_{i j \infty}^{D}$ & $\begin{array}{l}\text { Schiller-Naumann } \\
\text { method }\end{array}$ & $\begin{array}{cc}\frac{24}{R e_{p}}\left(1+0.15 \operatorname{Re}_{p}{ }^{0.687}\right) & 0<R e_{p}<1000 \\
0.44 & R e_{p}>1000\end{array}$ \\
\hline$f_{i j}^{D}$ & Richardson Zaki & $\left(1-\alpha_{p}\right)^{n}$ \\
\hline
\end{tabular}

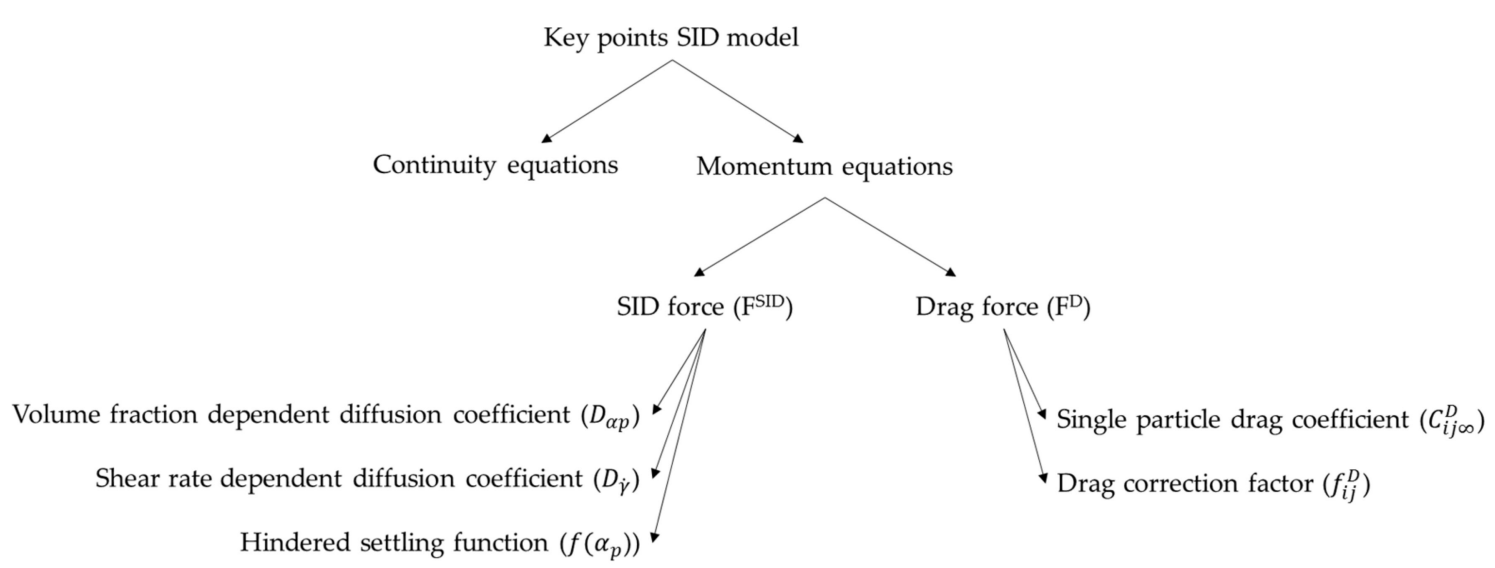

Figure 4. Flow chart of the most important steps taken in our shear induced diffusion model.

\subsection{Process Conditions}

In the STAR-CCM+ software, we make use of two-dimensional (2D) steady state simulations, which decreases the calculation time considerably. Parallel plate geometries are used that have a no slip boundary condition at the wall. Furthermore, by using a velocity inlet and a negative velocity outlet, we have the option to set the trans-membrane flux to a desired value. The nearest neighbor method, in which the two neighboring values adjacent to the wall are set equal, is used to prevent convergence issues.

The exact dimensions of the channel are different for the parameter studies that were carried out (see Table 3), but all of the channels are narrow in order for SID to occur. Typically, the pore size is much smaller than the length of the channel. Therefore, the grid size chosen for the height of the 
channel and dimensions of the pore are adjusted such that the process can be captured accurately (see grid refinement study in Appendix B). An overview of the dimensions is given in Table 3.

Table 3. Overview of the different dimensions used in the parameter studies.

\begin{tabular}{cccc}
\hline & & Particle Diameter $(\mu \mathrm{m})$ & Grid Cell Number \\
\hline Channel height & $50 \mu \mathrm{m}$ & 2 & 23 \\
Channel height & $100 \mu \mathrm{m}$ & 2 & 47 \\
Channel height & $100 \mu \mathrm{m}$ & 4 & 23 \\
Pore length & $20 \mu \mathrm{m}$ & 2 & 9 \\
\hline
\end{tabular}

\section{Results and Discussion}

In order to arrive at a complete process, the three parts of the overall system are first discussed below in individual sections: the non-porous entrance section, the porous section, and the recovery section in which the SID profile restores after being disturbed in the porous section.

\subsection{Entrance Section}

\subsubsection{Friction Factor}

In our previous study [10], it was shown that different diffusion coefficients can have a large influence on the development length of the SID profile, but not on the fully developed SID profile. It is expected that the friction factor that is used for both the drag force and the SID force has similar effects; therefore, this was tested first. In our model, we use the function: $f\left(\alpha_{p}\right)=\left(1-\alpha_{p}\right)^{2}\left(1-\widetilde{\alpha_{p}}\right)^{2}$ for the SID force (based on Vollebregt et al. [14]), and: $f_{i j}^{D}=\left(1-\alpha_{p}\right)^{n}$ for the drag force (standard in STAR-CCM+), and we investigated the sensitivity of the model for the functions that are used.

Figure 5 shows that a difference in friction factor does not influence the fully developed profile, but it does change the length needed to reach this profile. This was also observed by Miller et al. who changed the exponents in their function for $f\left(\alpha_{p}\right)$ [16]. In Figure 5, it can be seen that the position at which the particle volume fraction reaches its' equilibrium value is much shorter when using $f\left(\alpha_{p}\right)$ as compared to $f_{i j}^{D}$, and that is even more strongly so when used in conjunction with the SID force that as expected has a bigger influence on the development profile when compared to the drag force.

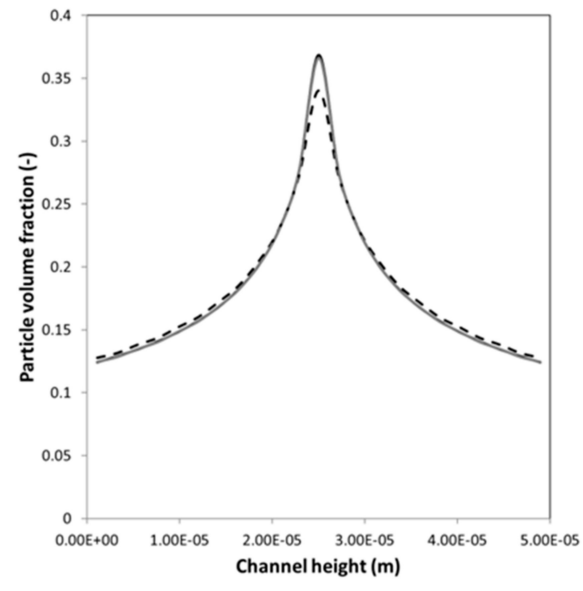

(a)

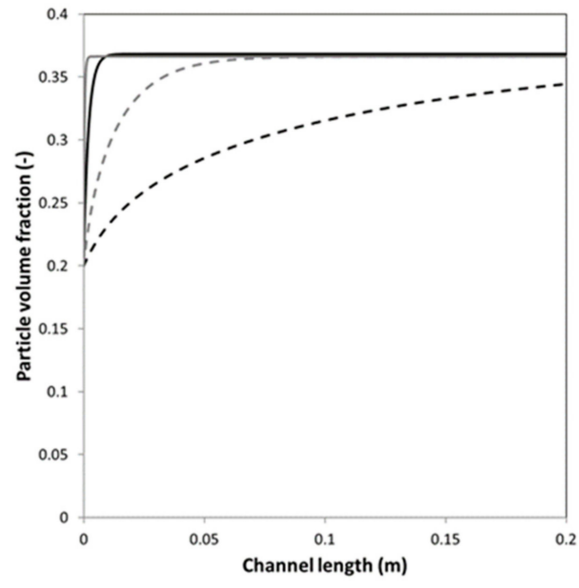

(b)

Figure 5. (a) Particle volume fraction versus the channel height and (b) the particle volume fraction in the center of the channel versus the channel length for different friction factors for both the drag and Shear induced diffusion (SID) force: $f\left(\alpha_{p}\right)$ for SID and $f_{i j}^{D}$ for drag (black solid line); $f\left(\alpha_{p}\right)$ for both SID and drag (grey solid line); $f_{i j}^{D}$ for both SID and drag (black dashed line); and, $f_{i j}^{D}$ for SID and $f\left(\alpha_{p}\right)$ for drag (grey dashed line) 
The choice of the friction coefficient is thus only of influence on the development length, but as Vollebregt and coworkers already mentioned that there are many different expressions for the friction factor in literature [14]. For the process that we eventually want to design, it is important to compare various situations, and we express our results in Section 3.3 relative to the entrance length.

\subsubsection{Parameter Case Study}

The four case studies that are shown in Table 4 were carried out to test the influence of velocity, channel height, particle diameter, and ratio between channel height and particle diameter. Table 5 shows the parameter ratios that are varied in the different cases.

Table 4. Four different case studies to look at the influence of different parameters.

\begin{tabular}{cccccc}
\hline Case & $\begin{array}{c}\text { Channel Height } \\
(\mathbf{H})(\boldsymbol{\mu m})\end{array}$ & Velocity $(\mathbf{m m} / \mathbf{s})$ & $\begin{array}{c}\text { Particle Diameter } \\
\left(\mathbf{D}_{\mathbf{p}}\right)(\boldsymbol{\mu m})\end{array}$ & Ratio $\mathbf{H} / \mathbf{D}_{\mathbf{p}}$ & $\begin{array}{c}\text { Channel } \\
\text { Length }(\mathbf{c m})\end{array}$ \\
\hline 1 & 50 & 1.0 & 2 & 25 & 4 \\
2 & 100 & 1.0 & 2 & 50 & 10 \\
3 & 100 & 1.0 & 4 & 25 & 8 \\
4 & 50 & 0.5 & 2 & 25 & 4 \\
\hline
\end{tabular}

Table 5. Parameter ratios that can be compared between the cases as shown in Table 4 .

\begin{tabular}{cc}
\hline Comparison between Cases & Parameters Compared \\
\hline 1 and 2 & Difference in $H / D_{p}$ ratio \\
1 and 3 & Difference in $H$ and $D_{p}$ at equal $H / D_{p}$ ratio \\
1 and 4 & Difference in velocity \\
\hline
\end{tabular}

The results for a 30\% bulk particle volume fraction are shown in Figure 6; the concentration at the center of the channel increases with an increasing channel length till it reaches a maximum, while the concentration at the wall decreases, which is indicative of shear induced diffusion taking place. Taking case 1 as our base case, an increase in channel height (case 2), and thus a change in $H / D_{p}$ ratio, results in reaching a different fully developed profile, as was also reported by Miller and coworkers [16]. Although the average particle volume fraction stays the same, the absolute number of particles is higher in case 2, which allows for more particle migration, leading to more particles in the center, and less particles near the wall. Besides, we see that the length needed to develop the SID profile changes, because particles need to travel further in case 2, which is in line with findings by Miller et al. [16]. Interestingly, at an equal channel height/particle diameter ratio (comparison between case 1 and 3), the entrance length changes while the fully developed profile does not differ, indicating the relative importance of these factors. Last, we checked the change in velocity but this did not influence the profile (case 1 and 4 in Figure 6 overlap), and indicates that the total number of interactions determines the concentration profile that is formed.

Furthermore, if we compare different bulk particle volume fractions (Figure 7), we conclude that the profiles develop faster at higher concentrations, and the differences in concentration at the centerline decrease with an increasing bulk particle volume fraction, while the opposite is true for the region near the wall. We believe this is caused by the limited freedom of movement that particles have at higher particle volume fractions; the increase in particle concentration that can be achieved in the center is a function of the initial particle concentration, as illustrated in Figure 8. At high volume fractions, the particle concentration in the center may be very close to the maximum packing density $\left(\alpha_{\max }=0.68\right)$, while the concentration at the wall is considerably reduced when compared to the average concentration. Both effects are beneficial for the novel process that we investigate, but they are only useful if the concentration profile re-establishes fast after being disturbed by a pore, as is investigated next. It is good to mention that these effects are directly related to pore placement design, which is discussed in the concluding section. 


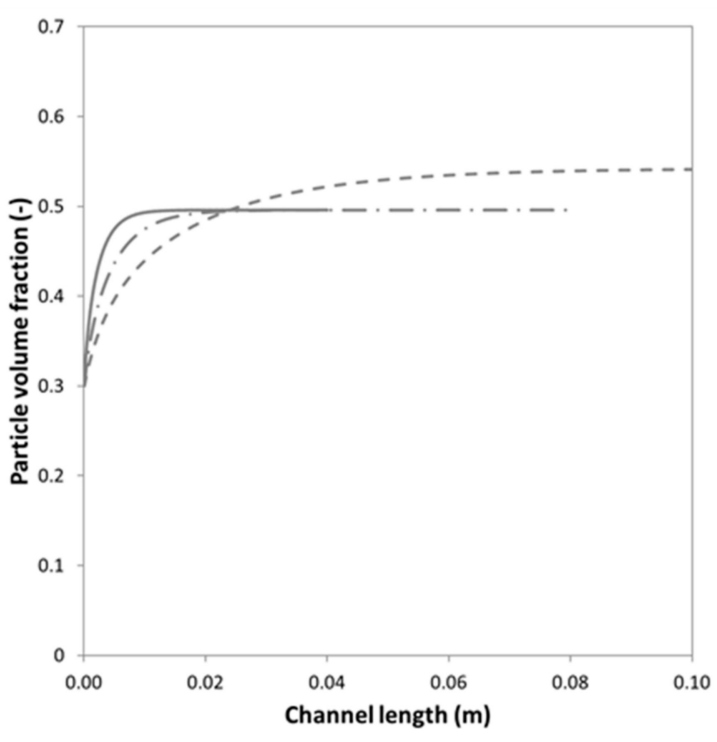

(a)

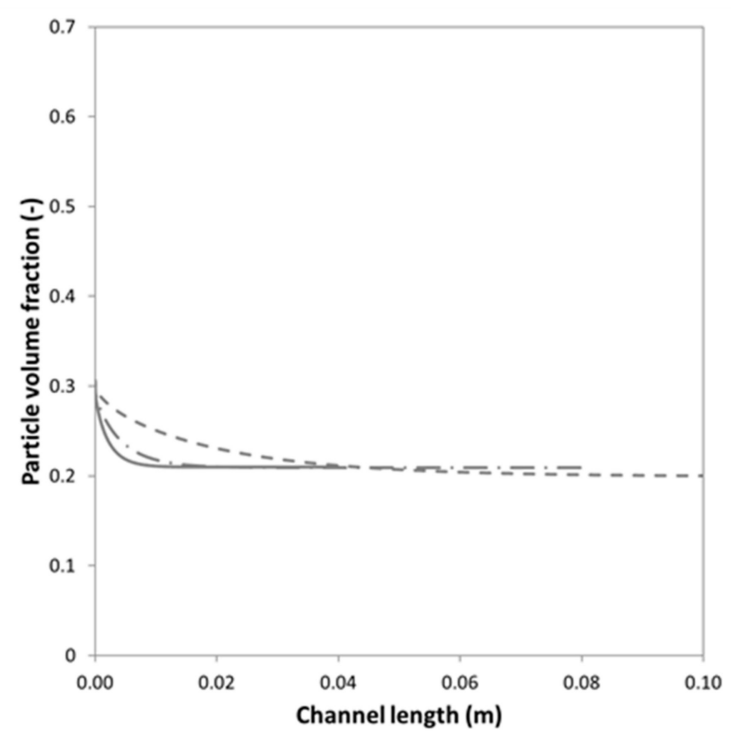

(b)

Figure 6. (a) Particle volume fraction versus the channel length at the channel centerline and (b) at $10 \%$ from the wall. Results are shown for a bulk particle volume fraction of $30 \%$ and for the cases as given in Table 4: case 1 (solid line); case 2 (dashed line); case 3 (dashed-dotted line); and, case 4 (dotted line). Note that case 1 and 4 overlap.

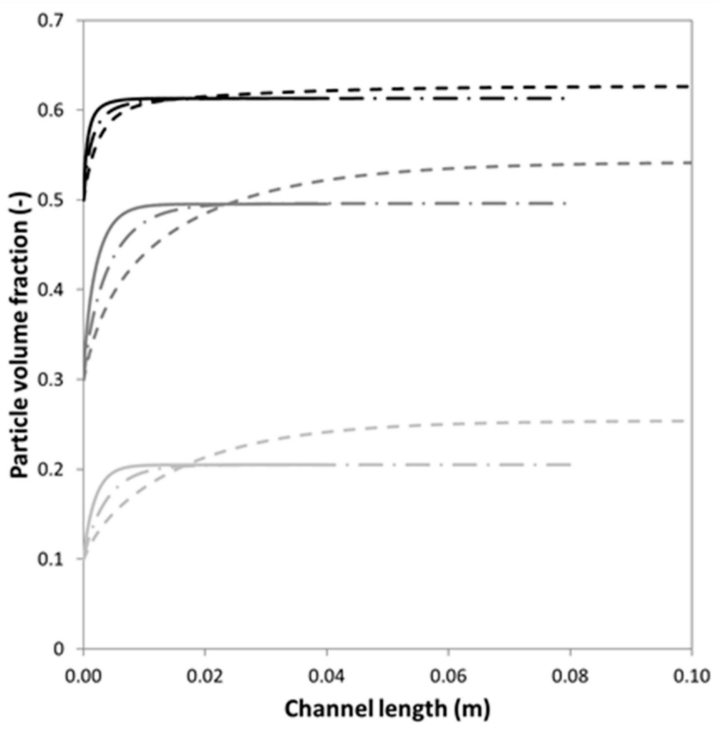

(a)

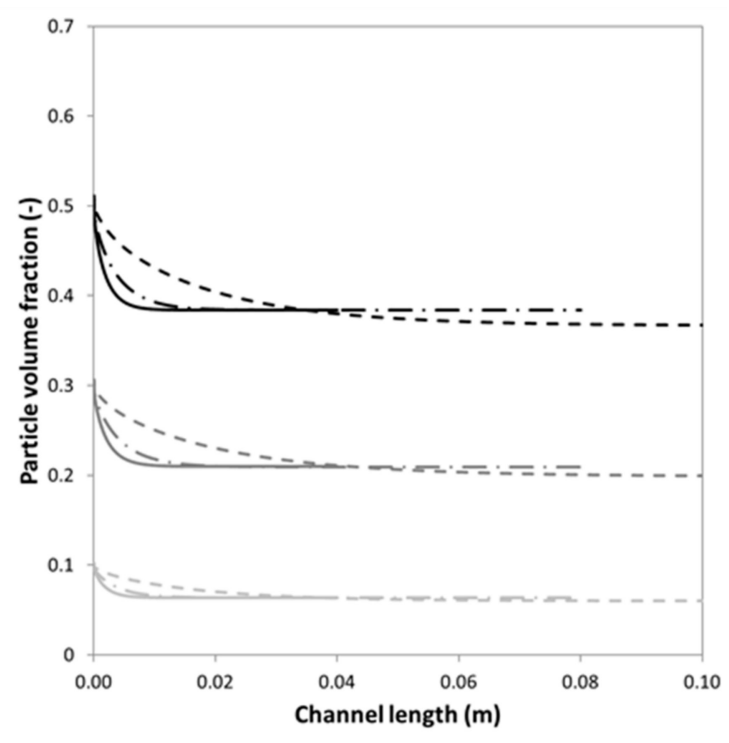

(b)

Figure 7. (a) Particle volume fraction versus the channel length at the channel centerline and (b) at $10 \%$ from the wall. Results are shown for three different bulk particle volume fractions: 0.1 (light grey); 0.3 (dark grey); 0.5 (black) and for the cases as given in Table 4: case 1 (solid line); case 2 (dashed line); case 3 (dashed-dotted line); and, case 4 (dotted line). Note, case 1 and 4 overlap. 


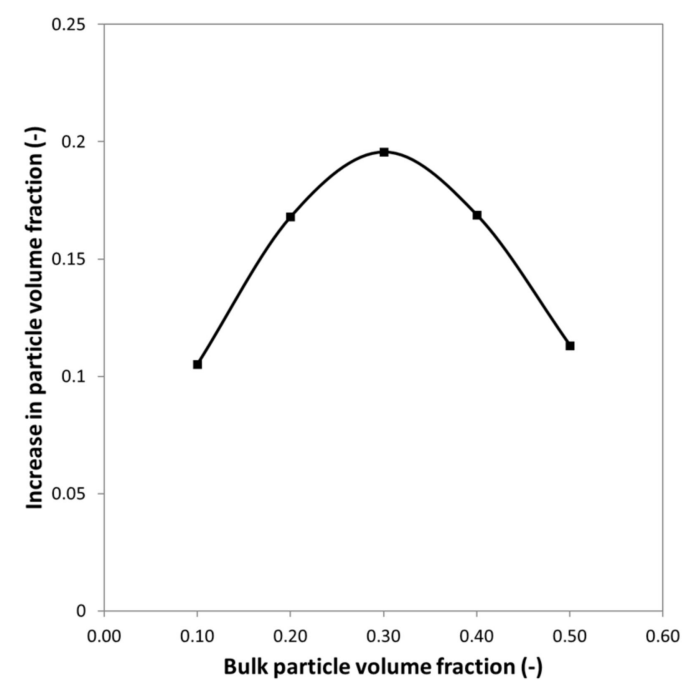

Figure 8. Increase in particle volume fraction at the center versus the bulk particle volume fraction for fully developed profiles for case 4 given in Table 4 .

\subsection{Porous Section}

A pore of $20 \mu \mathrm{m}$ length is added to the simulation grid. To compare separation efficiency, the transmission $(T)$ is determined, which is defined as:

$$
T=\frac{F_{m, p, p e r m a t e} / F_{m, p, \text { feed }}}{\text { Volume fraction extracted }}
$$

With $F_{m, p}$ the particle mass flux $\left(\mathrm{kg} / \mathrm{m}^{2} / \mathrm{s}\right)$. The results are shown in Figure 9 for two different channel heights and for permeate volumes that are between 2.5 and $10 \%$ of the feed, which are realistic values for membrane processes (albeit that for a single pore these are impressive amounts). The transmission ranges from $59 \%$ to $78 \%$ for different channel heights and particle concentrations in the feed. For higher channels, the transmission will be slightly lower, which is consistent with the findings that are discussed in Section 3.1.2. At high feed volume fraction, the concentration in the center of the channel is close to the maximum packing density, and therefore relatively more particles will be present near the wall. This results in a higher transmission, as was also expected based on the results that are shown in Figure 6.

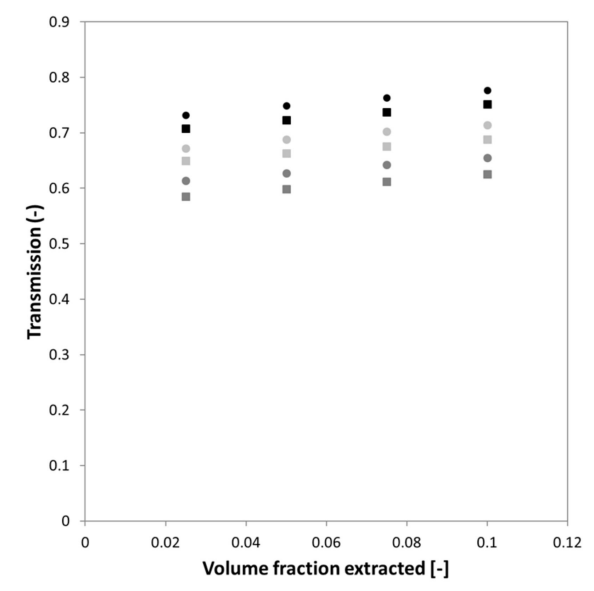

Figure 9. Transmission versus the volume fraction taken form the inlet. Results are shown for a channel height of 50 (circles) and 100 (squares) $\mu \mathrm{m}$ and for three different bulk particle volume fractions: 0.1 (dark grey); 0.3 (light grey); and, 0.5 (black). 


\subsection{Recovery Section}

For a single pore, the results are encouraging, and the next question that needs to be answered is how fast the concentration profile re-establishes after the pore, since it is disturbed by the porous section, see Figure 10 for an illustration. The results are shown in Figure 11; the method with which the recovery was characterized can be found in Appendix C. The center of the channel is taken as a reference point. Please note, the reference point chosen and the extent to which the SID profile is disturbed will have an influence on the results, therefore detailed analysis of membrane design are part of ongoing research.

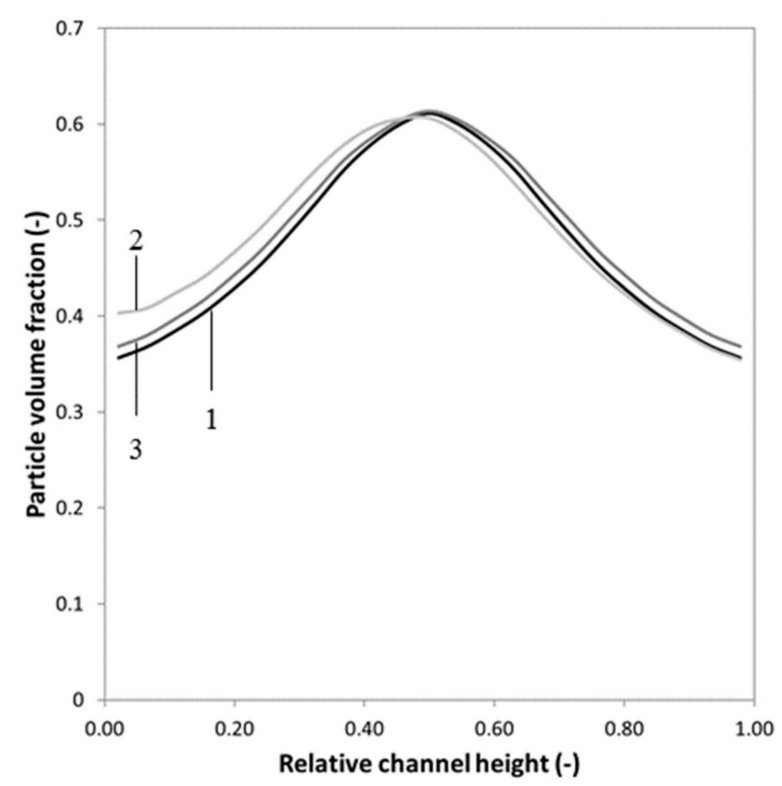

Figure 10. Particle volume fraction versus the relative channel height. The graph gives an indication of the shift in the SID profile of a suspension with a $50 \%$ bulk particle volume fraction: fully developed SID profile before the pore at $9.5 \mathrm{~cm}$ (black line, 1); disturbed SID profile just after the pore at $\sim 10 \mathrm{~cm}$ (light grey line, 2) and the restored SID profile after the pore at $19.5 \mathrm{~cm}$ (dark grey line, 3 ).

Figure 11 shows the relative development length after the pore when compared to the entrance section for different volume fractions extracted, and for bulk particle volume fractions of 10 and 30 percent. The values for reaching $95 \%$ of the fully developed profile for a bulk particle volume fraction of 50 percent were zero, indicating that the profiles re-establish extremely fast, which is essential for process design.

For lower bulk particle volume fractions, a higher development length is needed but it never exceeded $42 \%$ of that of the closed channel, even if as much as $10 \%$ of the liquid was removed. The trends that we see are as expected, with higher concentrations re-establishing faster, and this is also the case if less liquid is removed. In brief, extraction of more volume gives a greater disturbance of the SID profile, which therefore needs longer to recover.

The channel height does not have a great effect on the result; the narrower channels need, relative to the development length of the entrance section, slightly longer to re-establish but this effect is not as much as expected from Figure 7. This is caused by the fact that the profile is still rather established after the pore (and near the wall), while it needs to form from scratch at the entrance. When looking in the center of the channel, the effect of channel height is much clearer, since more particles need to be moved to re-establish the entire profile, as shown in Figure 12. For process design this is not very relevant since liquid is removed near to the wall, but we show the results here to illustrate that the extent to which the profile is distorted and recovers is a strong function of the position in the channel. 


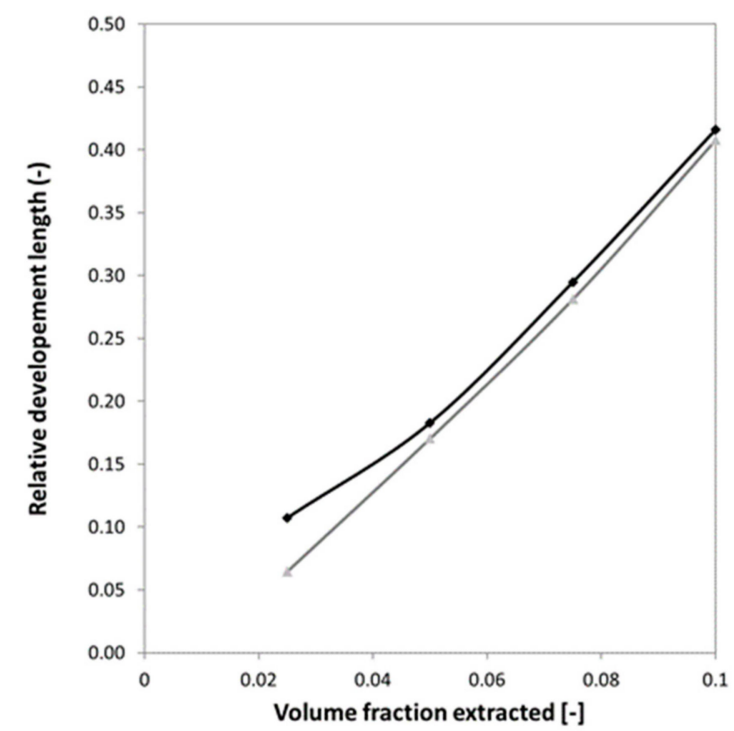

(a)

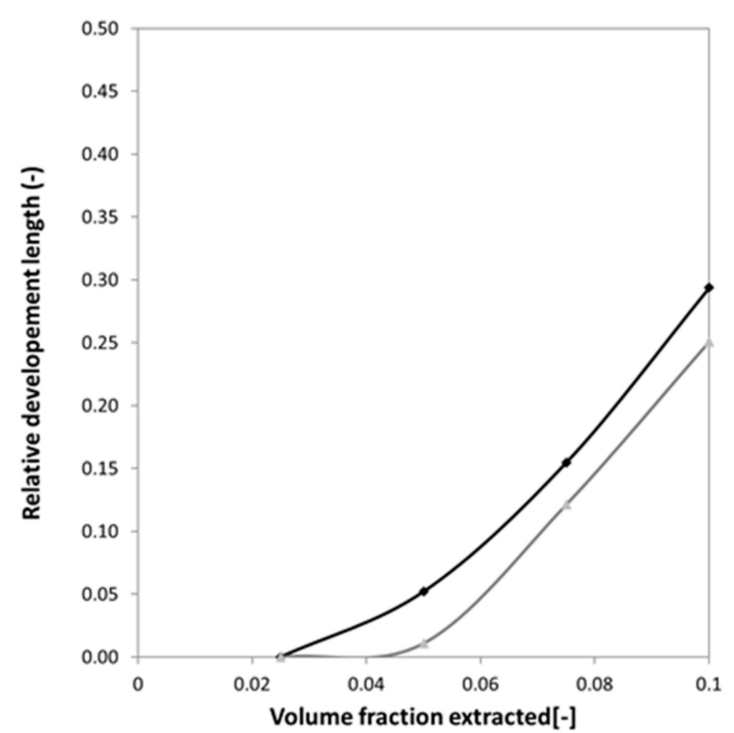

(b)

Figure 11. Relative development length at the center of the channel (95\%) between the recover section and the entrance section versus the volume fraction extracted from the inlet for a bulk particle volume fraction of $10 \%$ (a) and $30 \%$ (b). Each graph shows two different lines for the different channel heights: $50 \mu \mathrm{m}$ (black) and $100 \mu \mathrm{m}$ (grey).

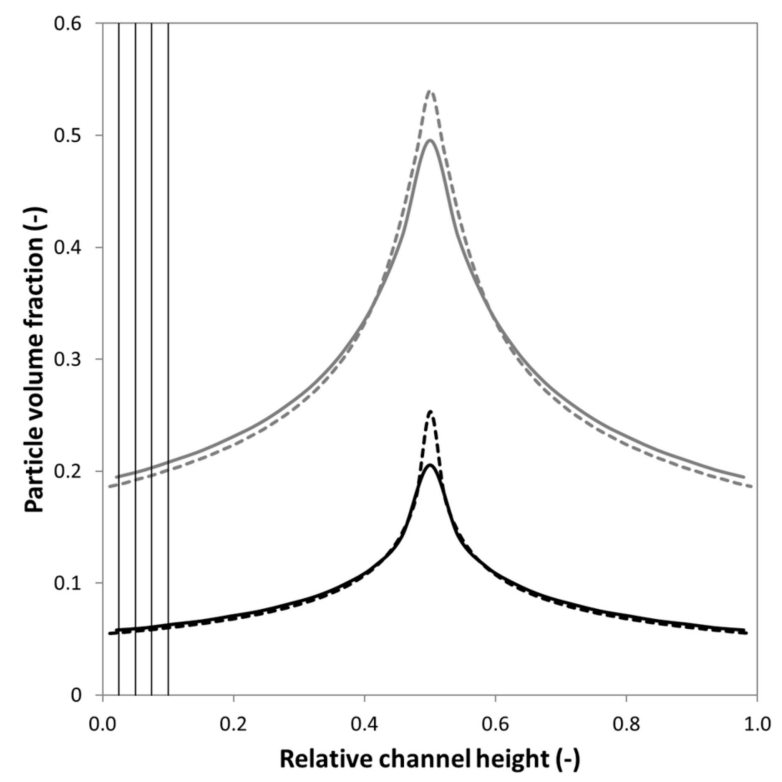

Figure 12. Relative particle volume fraction versus the relative channel height at a fully developed profile before the porous region for two different bulk particle volume fractions: $10 \%$ (black) and 30\% (grey) and two different channel heights: $50 \mu \mathrm{m}$ (solid line) and $100 \mu \mathrm{m}$ (dashed line). Vertical lines indicate the amount of volume extracted, from left to right: $2.5 \%, 5 \%, 7.5 \%$, and $10 \%$.

\subsection{Implications for Design}

The various aspects that are presented here are now related to process design in rather general terms. In order for the SID technology to work, the concentration profile needs to be established fast and within reasonable distance after entering the system. For all of the conditions investigated here $(10-50 \%$ particles, channel heights 50 and $100 \mu \mathrm{m})$, this requirement is met. The transmissions that are achieved in our systems were for monodisperse particles. We expect that if applied for 
fractionation of bi- or polydisperse dispersions the system will become even more interesting. Last but not least, the concentration profile re-established fast after the pore, and this indicates that in a full process, multiple pores can be placed within realistic distances from each other. Therewith, the overall productivity of the process can be enhanced considerably, as we hope to establish in future work that is directed toward the simulation of multiple pores leading to detailed design of porous regions.

\section{Conclusions}

Through simulations, we showed that shear induced diffusion can be used in novel technology for concentration of suspensions. The ratio of channel height and particle diameter was found to influence the channel length that is needed for the concentration profile to establish. Similar trends were found when a pore was added to the simulation grid. Particles are transmitted through the pores at concentrations that are considerably lower than the bulk concentration, and it is expected that these effects are going to be more prominent for bi- or poly-disperse suspensions. After the pore, the concentration profile re-established fast, and in all cases, convincing values were found indicating that pores can be positioned at realistic distances from each other as also discussed in the previous section. This leads us to conclude that the results that are obtained here form a good foundation for more detailed design studies of the porous region, and the process as a whole.

Author Contributions: Conceptualization was carried out by I.D. and K.S.; I.D. used the simulation methodology developed in a previous study; the analysis was done by I.D. and K.S.; The first draft was written by I.D.; the draft was reviewed by K.S. and revised by I.D.; the project was supervised by K.S.; the Acquisition of funding was done by K.S.

Acknowledgments: This work is supported by NanoNextNL, a micro and nanotechnology consortium of the Government of The Netherlands and 130 partners.

Conflicts of Interest: The authors declare no conflict of interest.

\section{Appendix A. List of Symbols}

\begin{tabular}{|c|c|c|}
\hline Symbol & Description & \\
\hline$a$ & Particle radius & $(\mathrm{m})$ \\
\hline$a_{i j}$ & Interfacial area density & $(1 / \mathrm{m})$ \\
\hline$A_{i j}^{D}$ & Linearized drag coefficient & $\left(\mathrm{Pa} \cdot \mathrm{s} / \mathrm{m}^{2}\right)$ \\
\hline$C_{i j}^{D}$ & Standard drag coefficient & $(-)$ \\
\hline$C_{i j \infty}^{D}$ & Single particle drag coefficient & \\
\hline$D_{\alpha_{p}}$ & Volume fraction dependent diffusion coefficient & $\left(\mathrm{m}^{2} / \mathrm{s}\right)$ \\
\hline$D_{\dot{\gamma}}$ & Shear rate dependent diffusion coefficient & $\left(\mathrm{m}^{2}\right)$ \\
\hline$f_{i j}^{D}$ & Drag correction factor & $(-)$ \\
\hline$f\left(\alpha_{p}\right)$ & Hindered settling function & $(-)$ \\
\hline $\mathrm{F}_{\mathrm{m}, \mathrm{p}}$ & Particle mass flux & $\left(\mathrm{kg} /\left(\mathrm{m}^{2} \cdot \mathrm{s}\right)\right)$ \\
\hline$F_{p f}^{D}$ & $\begin{array}{l}\text { Drag force on particle phase due to the fluid } \\
\text { phase }\end{array}$ & $\left(\mathrm{N} / \mathrm{m}^{3}\right)$ \\
\hline$F^{S I D}$ & Force due to shear induced diffusion & $\left(\mathrm{N} / \mathrm{m}^{3}\right)$ \\
\hline $\mathrm{g}$ & Gravity vector & $\left(\mathrm{m} / \mathrm{s}^{2}\right)$ \\
\hline$M$ & Mobility & $\left(\mathrm{m}^{2} /(\mathrm{Pa} \cdot \mathrm{s})\right)$ \\
\hline$p$ & Pressure (assumed equal in both phases) & $(\mathrm{Pa})$ \\
\hline$T$ & Transmission & $(-)$ \\
\hline$v_{g}$ & Grid velocity & $(\mathrm{m} / \mathrm{s})$ \\
\hline$v_{i}$ & Velocity of phase i & $(\mathrm{m} / \mathrm{s})$ \\
\hline \multicolumn{3}{|c|}{ Greek symbols } \\
\hline Symbol & Description & \\
\hline$\alpha_{i}$ & Volume fraction of phase i & $(-)$ \\
\hline$\alpha_{\max }$ & Maximum packing density & $(-)$ \\
\hline$\widetilde{\alpha_{p}}$ & Relative volume fraction $\left(\frac{\alpha_{p}}{\alpha_{\max }}\right)$ & $(-)$ \\
\hline$\dot{\gamma}$ & Shear rate & $(1 / s)$ \\
\hline$\eta_{i}$ & Viscosity of phase i & (Pa s) \\
\hline$[\eta]$ & Intrinsic viscosity & $(-)$ \\
\hline$\rho_{i}$ & Density of phase i & $\left(\mathrm{kg} / \mathrm{m}^{3}\right)$ \\
\hline$\tau_{i}$ & Molecular stresses & $(\mathrm{Pa})$ \\
\hline
\end{tabular}




\section{Appendix B. Grid Refinement Study}

Different pore geometries are considered for the parameter studies (Table A1) and therefore several grid refinement studies needed to be done, of which the results can be found in Figures A1-A4. Grid refinement study for case 4: the length and height of the pore. The relative particle volume fraction versus the channel height, measured at the center of the pore in the vertical (a) and horizontal (b) direction. The grid cell number for both the height (h) and the length (l) is changed: $h=5$ and $l=9$ (black solid line); $\mathrm{h}=7$ and $\mathrm{l}=9$ (grey solid line); $\mathrm{h}=9$ and $\mathrm{l}=9$ (black dashed line); $\mathrm{h}=11$ and $\mathrm{l}=9$ (grey dashed line); $\mathrm{h}=9$ and $\mathrm{l}=5$ (black dashed-dotted line), $\mathrm{h}=9$ and $\mathrm{l}=7$ (grey dashed-dotted line) and $h=9$ and $1=7$ (black dashed-double dotted line).Figure A4. Note that for both the length and height of the pore grid refinement was tested. It can be concluded that the grid sizes given in Table 3 are chosen appropriately.

Table A1. Overview of the different dimensions used in the parameter studies.

\begin{tabular}{cccc}
\hline Case & Channel Height $(\mu \mathrm{m})$ & Pore Height and Length $(\mu \mathrm{m})$ & Particle Diameter $(\mu \mathrm{m})$ \\
\hline 1 & 50 & - & 2 \\
2 & 100 & - & 2 \\
3 & 100 & - & 4 \\
4 & - & 20 & 2 \\
\hline
\end{tabular}

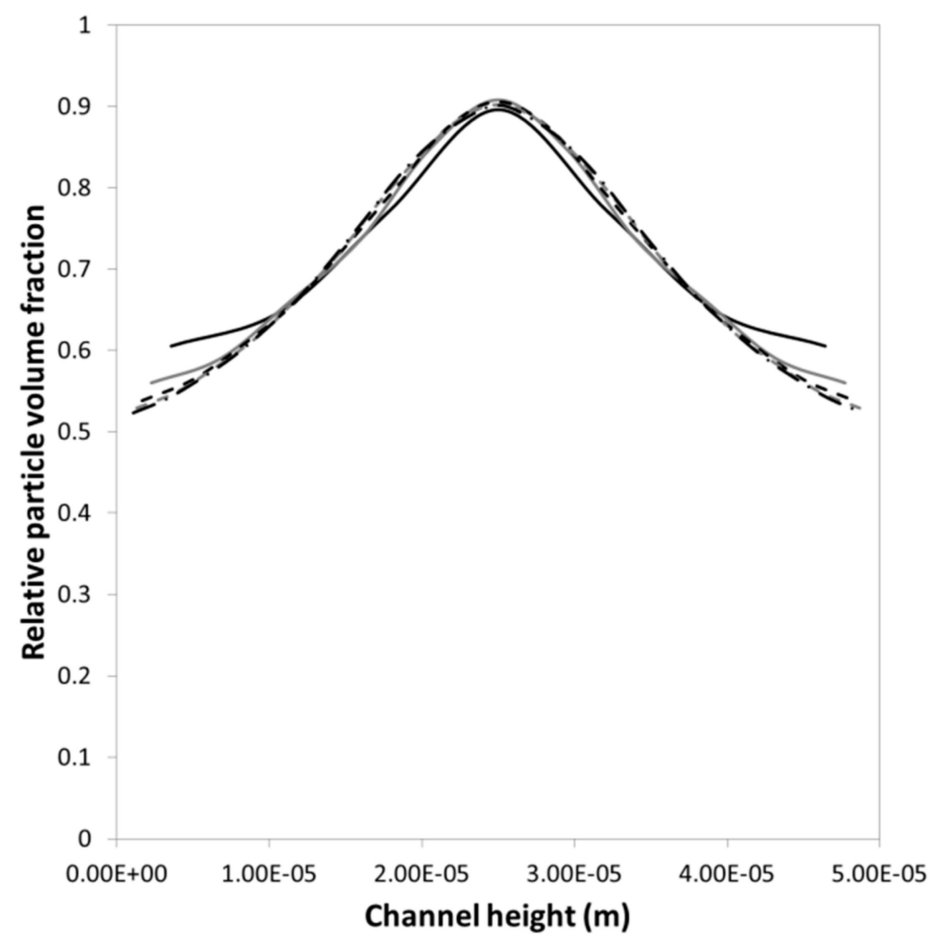

Figure A1. Grid refinement study for case 1. The relative particle volume fraction versus the channel height, measured $2.5 \mathrm{~cm}$ from the channel entrance. The grid cell number of the channel height is changed: 7 grid cells (black solid line); 11 grid cells (grey solid line); 15 grid cells (black dashed line); 19 grid cells (grey dashed line) and 23 grid cells (black dashed-dotted line) (Graph is reprinted from Separation and Purification Technology, 192, I. Drijer; T. van de Laar; H.M. Vollebregt and C.G.P.H. Schroën, From highly specialised to generally available modelling of shear induced particle migration for flow segregation based separation technology, 99-109, 2018, with permission from Elsevier). 


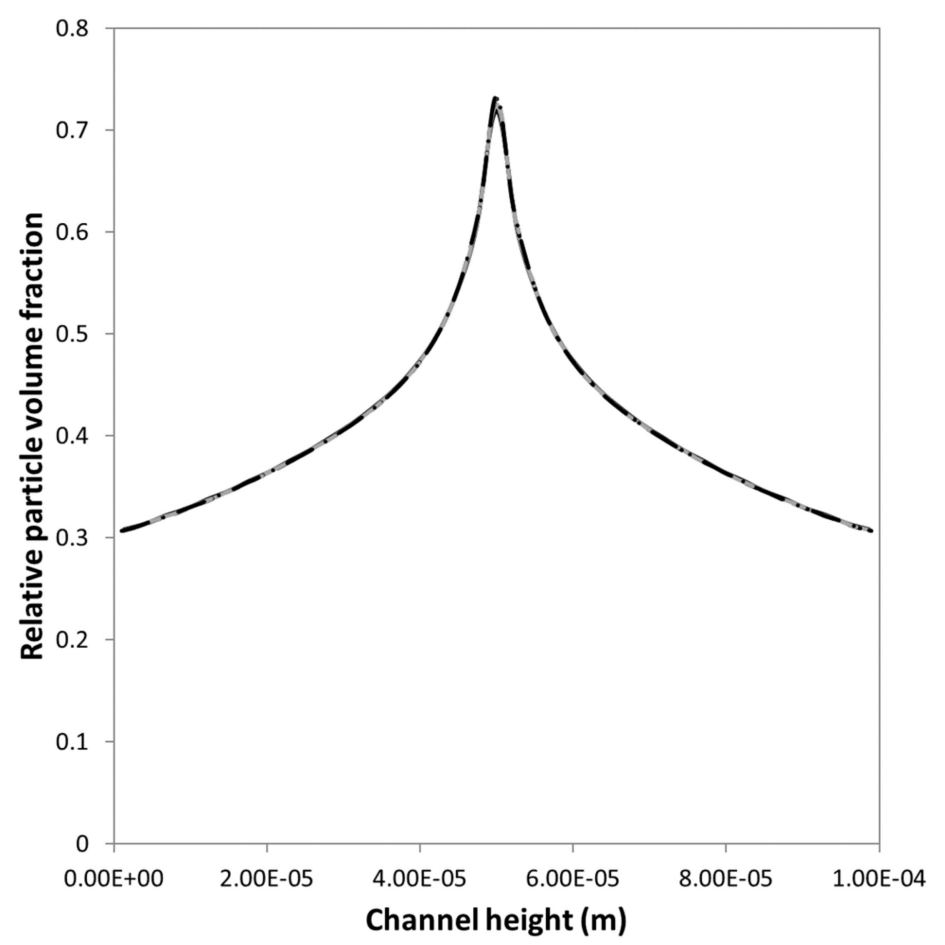

Figure A2. Grid refinement study for case 2. The relative particle volume fraction versus the channel height, measured $2.5 \mathrm{~cm}$ from the channel entrance. The grid cell number of the channel height is changed: 37 grid cells (black solid line); 41 grid cells (grey solid line); 45 grid cells (black dashed line); 47 grid cells (grey dashed line) and 49 grid cells (black dashed-dotted line).

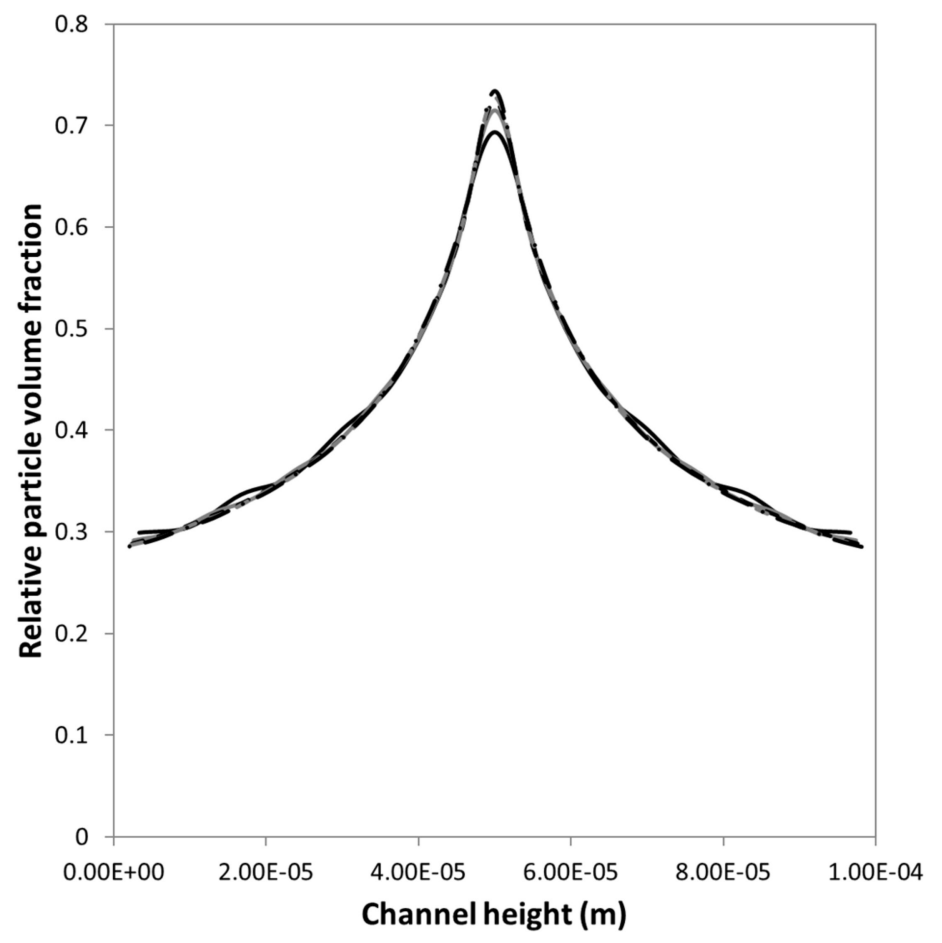

Figure A3. Grid refinement study for case 3. The relative particle volume fraction versus the channel height, measured $2.5 \mathrm{~cm}$ from the channel entrance. The grid cell number of the channel height is changed: 15 grid cells (black solid line); 19 grid cells (grey solid line); 21 grid cells (black dashed line); 23 grid cells (grey dashed line) and 27 grid cells (black dashed-dotted line). 


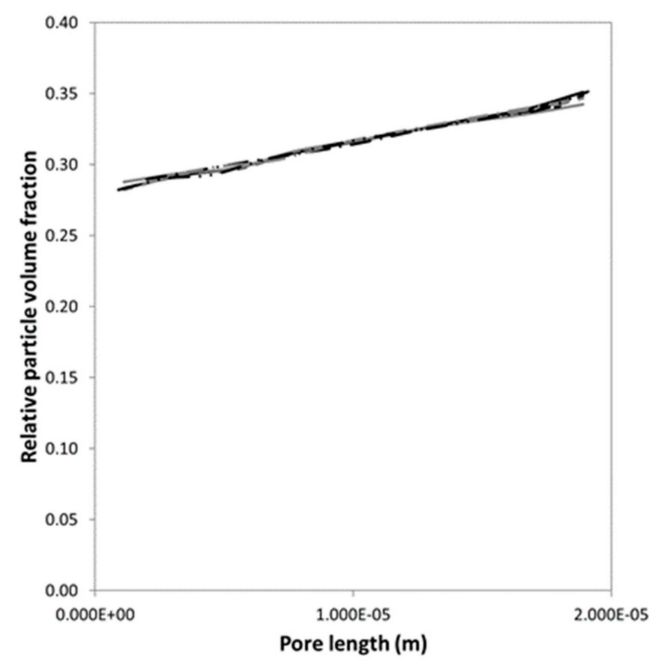

(a)

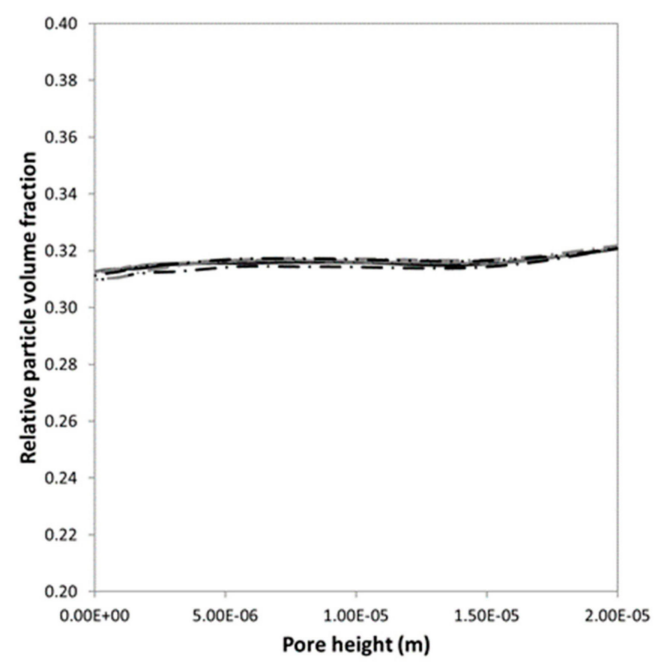

(b)

Figure A4. Grid refinement study for case 4: the length and height of the pore. The relative particle volume fraction versus the channel height, measured at the center of the pore in the vertical (a) and horizontal (b) direction. The grid cell number for both the height $(\mathrm{h})$ and the length (l) is changed: $\mathrm{h}=5$ and $\mathrm{l}=9$ (black solid line); $\mathrm{h}=7$ and $\mathrm{l}=9$ (grey solid line); $\mathrm{h}=9$ and $\mathrm{l}=9$ (black dashed line); $\mathrm{h}=11$ and $\mathrm{l}=9$ (grey dashed line); $\mathrm{h}=9$ and $\mathrm{l}=5$ (black dashed-dotted line), $\mathrm{h}=9$ and $\mathrm{l}=7$ (grey dashed-dotted line) and $\mathrm{h}=9$ and $\mathrm{l}=7$ (black dashed-double dotted line).

\section{Appendix C. Characterization of Recovery Length}

The development length for both the entrance section and recovery section are determined at the center of the channel using 95\% of the value for a fully developed profile as a target (Figure A5); we chose this value because this profile is sufficiently developed to be used in practice. To be complete, we used a different method than the method introduced by Hampton and coworkers [24] because high correlations between the different parameters were obtained when using their method.

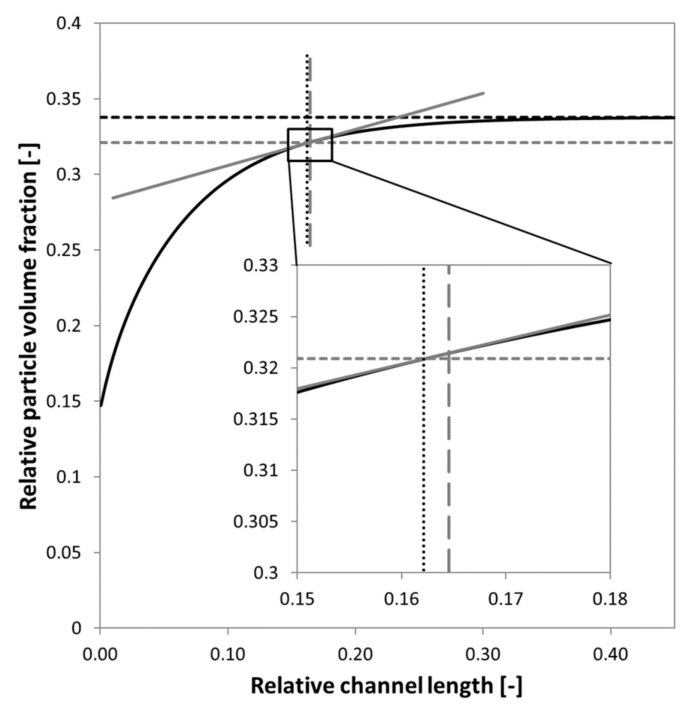

Figure A5. Schematic overview of how the entrance length is determined at the center of the channel and at $95 \%$ of the fully developed value. SID profile (black solid line); relative particle volume fraction for a fully developed profile (horizontal black dotted line); relative particle volume fraction at $95 \%$ (grey horizontal dotted line); tangent at $95 \%$ of the fully developed profile (grey solid line). 


\section{References}

1. Strathmann, H. Membrane Separation Processes: Current Relevance and Future Opportunities. AIChE J. 2001, 47, 1077-1087. [CrossRef]

2. Brans, G.; Schroën, C.G.P.H.; van der Sman, R.G.M.; Boom, R.M. Membrane Fractionation of Milk: State of the Art and Challenges. J. Membr. Sci. 2004, 243, 263-272. [CrossRef]

3. Van der Sman, R.G.M.; Vollebregt, H.M.; Mepschen, A.; Noordman, T.R. Review of Hypotheses for Fouling during Beer Clarification Using Membranes. J. Membr. Sci. 2012, 396, 22-31. [CrossRef]

4. Dijkshoorn, J.P.; Schutyser, M.A.I.; Wagterveld, R.M.; Schroën, C.G.P.H.; Boom, R.M. A Comparison of Microfiltration and Inertia-Based Microfluidics for Large Scale Suspension Separation. Sep. Purif. Technol. 2017, 173, 86-92. [CrossRef]

5. Belfort, G.; Davis, R.H.; Zydney, A.L. The Behavior of Suspensions and Macromolecular Solutions in Crossflow Microfiltration. J. Membr. Sci. 1994, 96, 1-58. [CrossRef]

6. Jaffrin, M.Y. Hydrodynamic Techniques to Enhance Membrane Filtration. Annu. Rev. Fluid Mech. 2012, 44, 77-96. [CrossRef]

7. Lubbersen, Y.S.; Schutyser, M.A.I.; Boom, R.M. Suspension Separation with Deterministic Ratchets at Moderate Reynolds Numbers. Chem. Eng. Sci. 2012, 73, 314-320. [CrossRef]

8. Van Dinther, A.M.C.; Schroën, C.G.P.H.; Boom, R.M. High-Flux Membrane Separation Using Fluid Skimming Dominated Convective Fluid Flow. J. Membr. Sci. 2011, 371, 20-27. [CrossRef]

9. Schroën, K.; van Dinther, A.; Stockmann, R. Particle Migration in Laminar Shear Fields: A New Basis for Large Scale Separation Technology? Sep. Purif. Technol. 2017, 174, 372-388. [CrossRef]

10. Drijer, I.; van de Laar, T.; Vollebregt, H.M.; Schroen, C.G.P.H. From Highly Specialised to Generally Available Modelling of Shear Induced Particle Migration for Flow Segregation Based Separation Technology. Sep. Purif. Technol. 2018, 192, 99-109. [CrossRef]

11. Davis, R.H. Modeling of Fouling of Crossflow Microfiltration Membranes. Sep. Purif. Methods 1992, 21, 75-126. [CrossRef]

12. Tiwari, P.; Antal, S.P.; Podowski, M.Z. Modeling Shear-Induced Diffusion Force in Particulate Flows. Comput. Fluids 2009, 38, 727-737. [CrossRef]

13. Asadi Tashvigh, A.; Fouladitajar, A.; Zokaee Ashtiani, F. Modeling Concentration Polarization in Crossflow Microfiltration of Oil-in-Water Emulsion Using Shear-Induced Diffusion; CFD and Experimental Studies. Desalination 2015, 357, 225-232. [CrossRef]

14. Vollebregt, H.M.; van der Sman, R.G.M.; Boom, R.M. Suspension Flow Modelling in Particle Migration and Microfiltration. Soft Matter 2010, 6, 6052-6064. [CrossRef]

15. Vollebregt, H.M.; van der Sman, R.G.M.; Boom, R.M. Model for Particle Migration in Bidisperse Suspensions by Use of Effective Temperature. Faraday Discuss. 2012, 158, 89-103. [CrossRef] [PubMed]

16. Miller, R.M.; Morris, J.F. Normal Stress-Driven Migration and Axial Development in Pressure-Driven Flow of Concentrated Suspensions. J. Nonnewton. Fluid Mech. 2006, 135, 149-165. [CrossRef]

17. Lyon, M.K.; Leal, L.G. An Experimental Study of the Motion of Concentrated Suspensions in Two-Dimensional Channel Flow. Part 2. Bidisperse Systems. J. Fluid Mech. 1998, 363, 57-77. [CrossRef]

18. Lyon, M.K.; Leal, L.G. An Experimental Study of the Motion of Concentrated Suspensions in Two-Dimensional Channel Flow. Part 1. Monodisperse Systems. J. Fluid Mech. 1998, 363, 25-56. [CrossRef]

19. Semwogerere, D.; Weeks, E.R. Shear-Induced Particle Migration in Binary Colloidal Suspensions. Phys. Fluids 2008, 20. [CrossRef]

20. Shauly, A.; Wachs, A.; Nir, A. Shear-Induced Particle Migration in a Polydisperse Concentrated Suspension. J. Rheol. 1998, 42, 1329-1348. [CrossRef]

21. Van Dinther, A.M.C.; Schroën, C.G.P.H.; Boom, R.M. Particle Migration Leads to Deposition-Free Fractionation. J. Membr. Sci. 2013, 440, 58-66. [CrossRef]

22. Van Dinther, A.M.C.; Schroën, C.G.P.H.; Boom, R.M. Separation Process for Very Concentrated Emulsions and Suspensions in the Food Industry. Innov. Food Sci. Emerg. Technol. 2013, 18, 177-182. [CrossRef] 
23. Van Dinther, A.M.C.; Schroën, C.G.P.H.; Imhof, A.; Vollebregt, H.M.; Boom, R.M. Flow-Induced Particle Migration in Microchannels for Improved Microfiltration Processes. Microfluid. Nanofluid. 2013, 15, 451-465. [CrossRef]

24. Hampton, R.E.; Mammoli, A.A.; Graham, A.L.; Tetlow, N.; Altobelli, S.A. Migration of Particles Undergoing Pressure-Driven Flow in a Circular Conduit. J. Rheol. 1997, 41, 621-640. [CrossRef] 